\title{
Treatment of diabetic coma with small intravenous insulin boluses
}

\author{
N CLUMECK, A DE TROYER, R NAEIJE, G SOMERS, L SMEKENS, E O BALASSE
}

British Medical fournal, 1976, 2, 394-396

\begin{abstract}
Summary
The clinical efficacy of small intravenous boluses of insulin in treating diabetic decompensation was tested in 23 patients presenting in either a ketoacidotic or a nonketotic diabetic coma. In addition to the usual ionic and fluid replacement, the patients received hourly intravenous injections of insulin 5 IU. This dose lowered blood glucose levels in all but two patients. In the patients who responded the percentage decrease in glycaemia was similar whatever the initial glucose concentration and averaged ( $\perp$ SE of mean) $50 \pm 3 \%$ in five hours. Close monitoring of insulin and glucose concentrations after intravenous insulin in three patients showed that despite the short half life of insulin the effect of the intravenous bolus lasted for about 60 minutes. The overall clinical effectiveness of this type of treatment is comparable to that of the other low-dose regimens. Owing to its simplicity, this technique of insulin administration seems most suitable for the routine treatment of diabetic coma.
\end{abstract}

\section{Introduction}

Recently the use of large doses of insulin for treating diabetic coma has been questioned. A regimen of hourly intramuscular injections of 5-10 IU has proved to be as effective in lowering blood glucose and ketone concentrations as conventional treatment with large doses. ${ }^{12}$ This treatment, although modified, has also been successfully used in children. ${ }^{3}$ Similarly, good results have been obtained with continuous intravenous infusions of 1-12 IU/hour, ${ }^{4-7}$ but infusions require special equipment that is not available in all hospitals.

These low-dose treatments are based on the knowledge that the optimum level of plasma insulin to promote glucose transport is small, lying between 20 and $200 \mathrm{mU} / 1 .{ }^{8}$ The use of repeated small intravenous boluses has been rejected ${ }^{14}{ }^{7}$ on the basis of the very short plasma half life of insulin (about four to five minutes). ${ }^{9}$ These theoretical objections against intermittent intravenous insulin treatment were not confirmed in a preliminary clinical study, which showed it to be as effective as the other low-dose regimens. ${ }^{10}$

This study analyses the clinical efficacy of small intravenous insulin boluses in the treatment of 23 consecutive cases of ketoacidotic and hyperosmolar non-ketotic diabetic coma.

Department of Internal Medicine, St Pierre Hospital, University of Brussels, B-1000 Brussels, Belgium

N CLUMECK, MD, assistant

A DE TROYER, MD, assistant

$R$ NAEIJE, $M D$, assistant

L SMEKENS, MD, assistant

E O BALASSE, MD, PHD, head of metabolic unit

Department of Internal Medicine, Brugmann Hospital, University of Brussels, Brussels, Belgium

G SOMERS, MD, assistant

\section{Patients and methods}

Twenty-three consecutive patients with severe uncontrolled diabetes were studied. All had plasma glucose levels above $19.4 \mathrm{mmol} / \mathrm{l}$ $(350 \mathrm{mg} / 100 \mathrm{ml}$ ), and all required immediate intravenous fluid and insulin. Nineteen patients were in ketoacidosis and four presented with a hyperosmolar non-ketotic decompensation. Six patients had never been treated with insulin. Six presented clinical evidence of infection and three others had signs of cardiac failure. One patient was in overt shock on admission, with a rectal temperature of $33^{\circ} \mathrm{C}$. Initial plasma glucose levels ranged from 20.0 to $96.0 \mathrm{mmol} / 1(360-1730 \mathrm{mg} / 100 \mathrm{ml})$ (mean $\pm S E$ of mean: $44.5 \pm 4.4 \mathrm{mmol} / \mathrm{l}(801 \pm 80 \mathrm{mg} / 100 \mathrm{ml})$ ). Arterial blood $\mathrm{pH}$ ranged from 6.75-7.40 (mean: $7 \cdot 09 \pm 0.037$ ) and serum potassium from $2 \cdot 1 \cdot 8 \cdot 3 \mathrm{mmol}(\mathrm{mEq}) / 1$ (mean : $5 \cdot 3 \pm 0 \cdot 4 \mathrm{mmol} / \mathrm{l}$ ). In the eight ketoacidotic patients in whom it was determined $\beta$ hydroxybutyrate ranged from $3 \cdot 29$ to $15 \cdot 14 \mathrm{mmol} / 1(34 \cdot 2-158 \mathrm{mg} / 100$ ml) (mean: $9.37 \pm 1.28 \mathrm{mmol} / 1(97.5 \pm 13.3 \mathrm{mg} / 100 \mathrm{ml})$ ), free fatty acids from 0.77 to $2.74 \mathrm{mmol} / \mathrm{l}$ (mean: $1.77 \pm 0.28 \mathrm{mmol} / \mathrm{l}$ ), and glycerol from 0.32 to $1 \cdot 16 \mathrm{mmol} / 1(2 \cdot 9-10.7 \mathrm{mg} / 100 \mathrm{ml}$ ) (mean: $0.40 \pm 0.14 \mathrm{mmol} / \mathrm{l}(3.7 \pm 1.3 \mathrm{mg} / 100 \mathrm{ml}))$.

During treatment plasma glucose was measured every hour and serum electrolytes every two hours. Plasma immunoreactive insulin was assayed according to the method of Herbert et al, ${ }^{11}$ and plasma $\beta$-hydroxybutyrate was determined enzymatically. ${ }^{12}$

All patients were treated with insulin and intravenous fluids.

Insulin-Whatever the biochemical values on admission, $5 \mathrm{IU}$ of insulin was given intravenously every hour as a single bolus with no initial loading dose. Once the blood sugar level had reached $13.9 \mathrm{mmol} / 1$ $(250 \mathrm{mg} / 100 \mathrm{ml})$ the intravenous insulin boluses were stopped and insulin was administered subcutaneously every six hours according to glycosuria, with an initial dose of $10 \mathrm{IU}$.

Intravenous fluids and electrolytes-Physiological saline (0.154-M) was given at the rate of 1 litre in 60 minutes then $500-750 \mathrm{ml}$ per hour; when plasma glucose had fallen below $13.9 \mathrm{mmol} / 1$ saline was replaced by dextrose $(50 \mathrm{~g} / \mathrm{l})$. When the initial arterial blood $\mathrm{pH}$ was less than $7 \cdot 10,500-1000 \mathrm{ml}$ sodium bicarbonate $(0 \cdot 166-\mathrm{M})$ was given instead of saline during the first hour of treatment. Potassium chloride $40 \mathrm{mmol}$ per litre of replacement fluid was started as soon as serum potassium levels were under $5 \mathrm{mmol} / 1$.

\section{Results}

Glucose-The individual plasma glucose responses to treatment are shown in fig 1 . The mean rate of fall calculated over the whole period of decreasing glucose concentration was $4.3 \mathrm{mmol} / \mathrm{l} / \mathrm{hour}(77 \mathrm{mg} / 100$ $\mathrm{ml} /$ hour). The percentage fall from initial values tended to be similar whatever the initial glucose level and averaged $50 \pm 3 \%$ in five hours. Glucose response was apparently unrelated to the severity of acidosis or history of insulin treatment. Only two patients did not respond adequately to treatment with $5 \mathrm{IU} /$ hour. One was in severe shock, with anuria and hypothermia $\left(33^{\circ} \mathrm{C}\right)$ on admission. The fall in plasma glucose level was unusually low ( $28 \%$ in five hours; (case 1 , fig $1 \mathrm{~B}$ ), and the dose of $5 \mathrm{IU} /$ hour was certainly of borderline efficacy. Clinical recovery, however, was excellent. Presumably a dose of $10 \mathrm{IU} /$ hour would have been better. A second patient (case 2) did not respond at all to $5 \mathrm{IU} /$ hour. In addition to her diabetic decompensation, she was severely ill with bacterial endocarditis, cardiac and renal failure, and obesity. She was obviously insulin-resistant before the acute episode since decompensation developed while she was treated with 120 IU/day. Insulin $20 \mathrm{IU} /$ hour was needed to obtain an adequate glucose response.

Ketone bodies- $\beta$-Hydroxybutyrate concentrations fell steadily from an average admission value of $9.37 \mathrm{mmol} / 1(97.5 \mathrm{mg} / 100 \mathrm{ml}$ ) (in eight patients) (fig 2). Some patients were still fairly ketotic when their hyperglycaemia was controlled (glucose level $<13.9 \mathrm{mmol} / \mathrm{l}$ ).

Effect of insulin injections on plasma insulin and glucose concentrations-To define precisely the pattern of plasma insulin and glucose changes during treatment we determined the concentration of these 


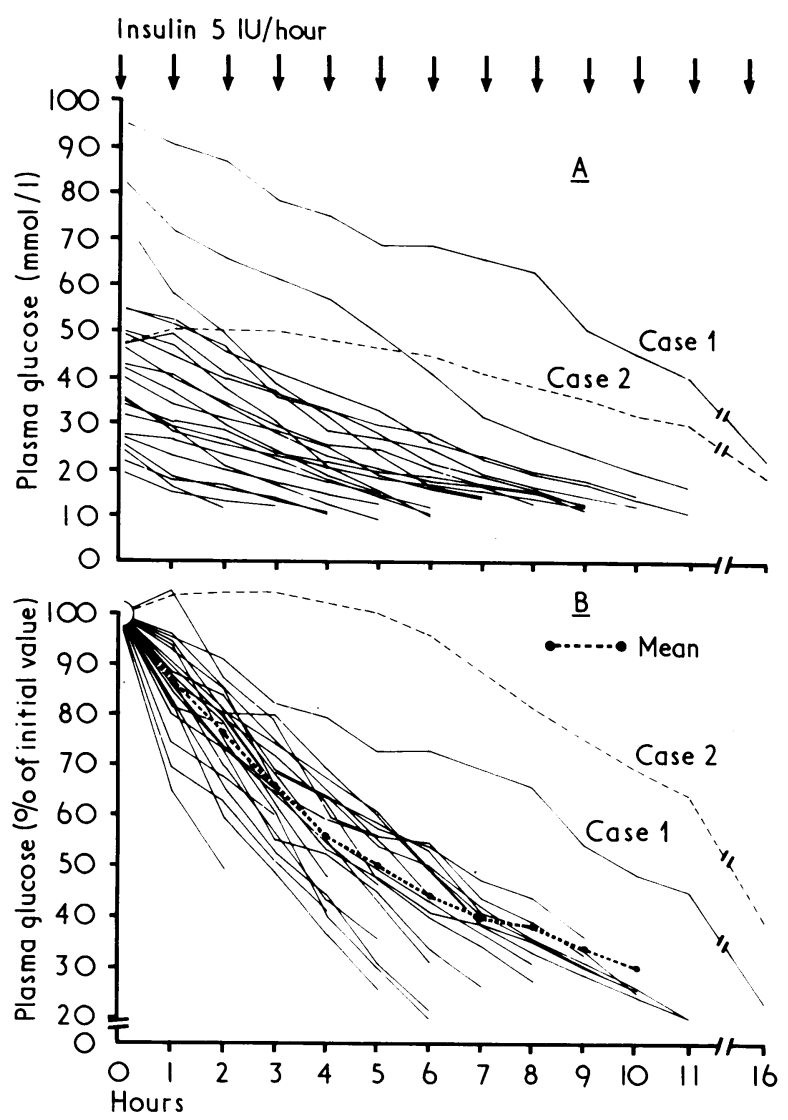

FIG 1-Plasma glucose levels (A) and values as percentages of initial levels (B) during treatment with intravenous insulin boluses (5 IU/hour). One patient (case 2) was unresponsive to $5 \mathrm{IU} /$ hour and received increasing doses up to $20 \mathrm{IU} /$ hour from the 3 rd hour onwards; this patient's values were not included in the calculation of the mean curve in graph $B$.

Conversion: SI to traditional units-Glucose: $1 \mathrm{mmol} / 1 \approx 18 \mathrm{mg} / 100 \mathrm{ml}$

two substances every five minutes for two consecutive hours in three patients who had never received insulin before. The results are shown in the table. After an initial peak exceeding $600 \mathrm{mU} / \mathrm{l}$ insulinaemia rapidly decreased so that its concentration was below $50 \mathrm{mU} / 130$ minutes after the injection. Consequently the rate of fall of glycaemia was highest immediately after the insulin injection and decreased progressively until the next insulin injection.

Mortality-Two patients died several days after correction of their diabetic coma: one patient aged 70 died 20 days later from uncal herniation associated with cerebral emboli; the other patient, who was 83, suffered fatal bronchopneumonia four days after her diabetic decompensation.

\section{Discussion}

The use of small doses of insulin (less than $10 \mathrm{IU} /$ hour) for treating diabetic coma has been recently proposed by several workers. Both the intramuscular route ${ }^{1-3}$ and constant intravenous infusion have been used satisfactorily. ${ }^{4-8}$

The intramuscular route, however, has potential hazards. Insulin absorption may be delayed, especially in severely dehydrated and hypotensive patients. Glycaemia therefore tends to rise during the first few hours, ${ }^{13}$ and substantial amounts of insulin accumulated at the injection sites may be liberated into the blood stream when glycaemia has returned towards normal, thereby causing late hypoglycaemia.

Theoretically the constant intravenous infusion seems to be ideal. Constant and optimal plasma insulin levels can easily be obtained and the minute-to-minute fall in blood glucose concentration is probably very smooth. This method does have some disadvantages, however, when used in every-day hospital life. ${ }^{3}$ Firstly, a constant infusion device is needed; Alberti and

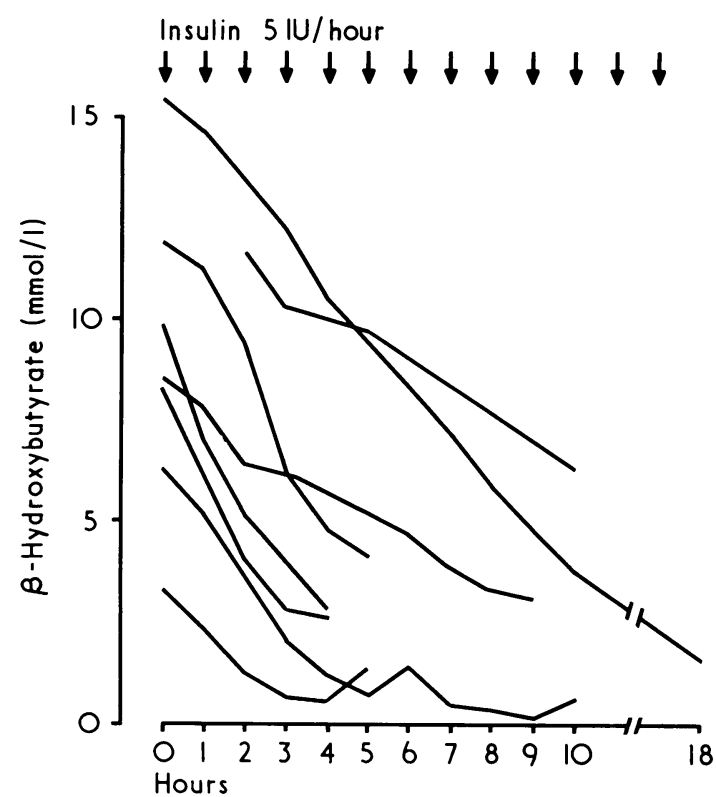

FIG 2-\$-Hydroxybutyrate concentrations in eight patients during treatment with intravenous insulin boluses. For each patient the last $\beta$-hydroxybutyrate determination was obtained when glycaemia had reached $13.9 \mathrm{mmol} / \mathrm{l}(250$ $\mathrm{mg} / 100 \mathrm{ml}$ ).

Conversion: SI to traditional units- $\beta$-Hydroxybutyrate: $1 \mathrm{mmol} / 1 \approx 10.4 \mathrm{mg} / 100 \mathrm{ml}$.

Plasma glucose (mmol/l) and insulin ( $m U / l)$ concentrations during two hours of treatment in three patients

\begin{tabular}{|c|c|c|c|c|c|c|}
\hline \multirow{2}{*}{$\begin{array}{c}\text { Time } \\
\text { (minutes) }\end{array}$} & \multicolumn{2}{|c|}{ Case 3} & \multicolumn{2}{|c|}{ Case 4} & \multicolumn{2}{|c|}{ Case 5} \\
\hline & Glucose & Insulin & Glucose & Insulin & Glucose & Insulin \\
\hline $\begin{array}{r}0 \\
5 \\
10 \\
15 \\
20 \\
25 \\
30 \\
35 \\
40 \\
45 \\
50 \\
55 \\
60 \\
65 \\
70 \\
75 \\
80 \\
85 \\
90 \\
95 \\
100 \\
105 \\
110 \\
115 \\
120\end{array}$ & $\begin{array}{l}74 \cdot 6 \\
73 \cdot 8 \\
69 \cdot 6 \\
74 \cdot 4 \\
70 \cdot 1 \\
70 \cdot 7 \\
67 \cdot 9 \\
64 \cdot 7 \\
63 \cdot 4 \\
61 \cdot 2 \\
61 \cdot 1 \\
59 \cdot 7 \\
60 \cdot 4 \\
59 \cdot 7 \\
55 \cdot 9 \\
55 \cdot 2 \\
53 \cdot 7 \\
50 \cdot 0 \\
44 \cdot 7 \\
49 \cdot 2 \\
49 \cdot 2 \\
47 \cdot 0 \\
47 \cdot 7 \\
44 \cdot 7 \\
46 \cdot 2\end{array}$ & $\begin{array}{r}0 \\
692 \\
391 \\
346 \\
150 \\
86 \\
41 \\
27 \\
20 \\
23 \\
11 \\
5 \\
0 \\
688 \\
324 \\
251 \\
114 \\
61 \\
40 \\
35 \\
23 \\
17 \\
11 \\
2 \\
4\end{array}$ & $\begin{array}{l}20 \cdot 0 \\
18.4 \\
16.5 \\
16.0 \\
16.0 \\
15.2 \\
15.0 \\
14.5 \\
14.5 \\
14 \cdot 2 \\
14 \cdot 2 \\
14.4 \\
14 \cdot 3 \\
13.2 \\
13.0 \\
13 \cdot 2 \\
12.5 \\
12.4 \\
12.0 \\
12.2 \\
12.0 \\
11.8 \\
11.5 \\
11.8\end{array}$ & $\begin{array}{r}8 \\
610 \\
250 \\
108 \\
54 \\
29 \\
19 \\
15 \\
13 \\
12 \\
11 \\
28 \\
17 \\
614 \\
317 \\
140 \\
76 \\
37 \\
27 \\
21 \\
18 \\
16 \\
15 \\
13\end{array}$ & $\begin{array}{l}35 \cdot 4 \\
34 \cdot 7 \\
34 \cdot 3 \\
34 \cdot 0 \\
32 \cdot 5 \\
30 \cdot 1 \\
30 \cdot 4 \\
30 \cdot 1 \\
29 \cdot 4 \\
28 \cdot 6 \\
28 \cdot 6 \\
26 \cdot 5 \\
28 \cdot 3 \\
26 \cdot 9 \\
25 \cdot 8 \\
25 \cdot 5 \\
26 \cdot 2 \\
25 \cdot 5 \\
25 \cdot 8 \\
25 \cdot 5 \\
25 \cdot 5 \\
25 \cdot 5 \\
25 \cdot 5\end{array}$ & $\begin{array}{r}11 \\
886 \\
214 \\
105 \\
39 \\
34 \\
21 \\
18 \\
11 \\
9 \\
13 \\
0 \\
574 \\
267 \\
83 \\
41 \\
31 \\
25 \\
18 \\
15 \\
12 \\
8 \\
12 \\
15\end{array}$ \\
\hline
\end{tabular}

Conversion: SI to traditional units-Glucose: $1 \mathrm{mmol} / 1 \approx 18 \mathrm{mg} / 100 \mathrm{ml}$.

Hockaday ${ }^{14}$ have recently stated that insulin can easily be infused at a constant rate using a $\mathrm{Y}$ connector attached to the ordinary infusion through which fluid replacement is being given. But it is difficult in practice to keep the flow constant with an ordinary drip. Secondly, adsorption of insulin to glassware and tubing may be a problem so that the addition of albumin or other macromolecules to the insulin solution is a prudential measure. ${ }^{15}$

The use of repeated intravenous insulin boluses shares with constant intravenous infusion the advantages of having an immediate action and preventing insulin accumulation. Nevertheless, the circulating insulin levels obtained with this technique fluctuate widely, with unnecessarily high levels immediately after the injection followed by a rapid disappearance of insulin from plasma. Therefore the action of the 5-IU bolus does not last longer than one hour and the rate of fall of plasma glucose during 
the treatment is not perfectly steady (see table). This disadvantage seems merely theoretical, however, and it is unlikely that it might be harmful. Good clinical results were obtained in our series of 23 patients: mortality was low and not directly related to the diabetic decompensation; the percentage fall in glycaemia with time was remarkably similar in most patients whatever the degree of initial hyperglycaemia or acidosis $(50 \pm 3 \%$ in five hours), and the pattern of glycaemic response can therefore be easily predicted for any given patient at the start of the treatment. Interestingly, the slower rates of decrease in glucose concentration were observed in three patients with cardiac failure who could not receive large amounts of fluid. This re-emphasises the fact that early and vigorous fluid replacement remains an essential part of the treatment of diabetic coma whatever the insulin regimen used. Hyperketonaemia took longer to correct than hyperglycaemia and several patients were still ketotic when glycaemia had returned to a level of about $13.9 \mathrm{mmol} / \mathrm{l}$ (fig 2). Similar observations were made by Soler et $a l^{13}$ irrespective of the mode of administration and the amount of insulin given to the patient. Finally, none of our patients showed late hypoglycaemia or hypokalemia.

The dose of $5 \mathrm{IU} /$ hour was effective in all but two cases: in one patient the decrease in plasma glucose was unusually low, and in the other injections of $20 \mathrm{IU} /$ hour were needed to obtain a significant hypoglycaemic action. This resistance to insulin was probably related to the severity of the clinical state; the first patient was in deep coma with severe dehydration, hypovolaemic shock, and hypothermia, and the second one presented bacterial endocarditis with multiple cerebral infarctions, and cardiac and renal failure. In the second patient relative insulin resistance existed before the acute episode since decompensation developed while she was treated with $120 \mathrm{IU} /$ day. Thus some patients may be refractory to these low-dose insulin regimens.

In conclusion, our results indicate that hourly intravenous boluses are a convenient and efficient way of administering insulin in the treatment of diabetic coma. The hormone can easily be injected through the tubing used for the fluid replacement. This mode of administration is much simpler than the constant infusion technique; even small hospitals with reduced medical staff should be able to apply this technique routinely. If, under careful monitoring, resistance to the standard dose of $5 \mathrm{IU} /$ hour occurs the insulin dose can easily be increased to 10-20 IU/hour or more if necessary. A clinical trial on the routine use of $20 \mathrm{IU} /$ hour is in progress.

We thank Dr Cornil for his constant interest; the nurses and medical staff of the intensive care unit for their help in caring for the patients; and Mrs M A Neef for her excellent technical help.

Requests for reprints should be addressed to Dr N Clumeck, Service de Médecine Interne, Hôpital Saint Pierre, 322 rue Haute, B-1000 Bruxelles, Belgium.

\section{References}

${ }^{1}$ Alberti, K G M M, Hockaday, T D R, and Turner, R C, Lancet, 1973, 2, 515.

${ }^{2}$ Kitabchi, A E, Ayyagari, V, and Guerra, S, Diabetes, 1975, 24, suppl No 2, p 396.

${ }^{3}$ Moseley, J, British Medical fournal, 1975, 1, 59.

${ }^{4}$ Kidson, W, et al, British Medical fournal, 1974, $2,691$.

5 Page, M McB, et al, British Medical fournal, 1974, 2, 687.

${ }^{6}$ Piters, K, Goodman, J, and Bessman, A, Diabetes, 1975, 24, suppl No 2, p 396.

'Semple, P F, White, C, and Manderson, W G, British Medical fournal, $1974,2,694$.

8 Sönksen, P H, et al, Lancet, 1966, 2, 155.

9 Turner, R C, et al, fournal of Clinical Endocrinology and Metabolism, 1971, 33, 279.

${ }^{10}$ Clumeck, N, et al, Lancet, 1975, 2, 416

${ }^{11}$ Herbert, V, et al, Fournal of Clinical Endocrinology and Metabolism, 1965, $25,1375$.

12 Williamson, D H, Mellanby, J, and Krebs, H A, Biochemical fournal, $1962,82,90$.

13 Soler, N G, et al, Lancet, 1975, 2, 1221.

${ }^{14}$ Alberti, K G M M, and Hockaday, T D R, Lancet, 1975, 2, 547.

${ }^{15}$ Kraegen, E W, et al, British Medical fournal, 1975, 3, 464.

\title{
Acute responsiveness to calcitonin in chronic renal failure
}

\author{
M COCHRAN, CARMEL J HILLYARD, G J DEW，T J MARTIN
}

British Medical fournal, 1976, 2, 396-398

of the initial plasma phosphate level but was unrelated to the initial plasma calcium level. Plasma hydroxyproline levels were not significantly different in the two groups and were unaffected by calcitonin. In 11 patients fasting plasma calcitonin levels were undetectable with an assay sensitive to $0.1 \mathrm{ug} / \mathrm{l}$. Calcitonin seems to have an acute effect in chronic renal failure which may not operate by arresting bone resorption but is dependent on the plasma phosphate concentration. phosphate levels, but in nine patients both concentrations were substantially reduced after calcitonin. This hypocalcaemic and hypophosphataemic effect was a function

Renal Unit, Northern General Hospital, Sheffield S10 2RX

M COCHRAN, MD, MRCP, senior medical registrar

Endocrine Unit, Royal Postgraduate Medical School, Hammersmith Hospital, London W12 OHS

CARMEL J HILLYARD, BSC, research assistant

Tissue Physiology, Strangeways Research Laboratory, Cambridge G J DEW, AIST, technical officer

Department of Chemical Pathology, University of Sheffield Medical School, Sheffield S10 2RX

T J MARTIN, MD, FRACP, professor of chemical pathology

\section{Introduction}

Calcitonin was discovered as a hypocalcaemic hormone, but there is no evidence to suggest that it has a role in regulating plasma calcium levels in normal adults. It acts by inhibiting bone resorption,,$^{12}$ and it is therefore not surprising that its hypocalcaemic effect is best seen when bone resorption is increased -for example, in stages of rapid growth or in conditions such as Paget's disease or thyrotoxicosis. ${ }^{3-5}$

The effectiveness of calcitonin in treating Paget's disease is based on its ability to inhibit osteoclastic bone resorption. ${ }^{3-6}$ Since parathyroid hormone-stimulated increases in bone resorption in patients with chronic renal failure may lead to painful bone disease and fractures, the present study was begun on the 